\title{
Propagation trend analysis of vertical cracks for typical section in Danjiangkou Dam
}

\author{
Yongfeng $\mathrm{Qi}^{1, \mathrm{a}}$, Jianhua Cui ${ }^{1, \mathrm{~b}}$ \\ ${ }^{1}$ Department of Material and Structure, Changjiang River Scientific Research Institute ,Wuhan, \\ China,430010 \\ aqiyf@mail.crsri.cn, bcuijh@mail.crsri.cn
}

Keywords: propagation trend; dam heightening; stress intensity factor; fracture toughness; full head; hydraulic fracturing.

\begin{abstract}
: vertical cracks may propagate through the whole dam under water pressure, which exist on the upstream of 18th section in Danjiangkou Dam. To solve the problems, stress intensity factor method of fracture mechanics is adopted, combing with three-dimensional finite element method. For different cracks treatment, propagation trend of old dam and new heightening dam is analyzed to give reference for designing reasonable treatment.
\end{abstract}

\section{Introduction}

As water resources engineering of Middle Route Project of South-North Water Transfer Project. The old dam is heightened from $162 \mathrm{~m}$ to $176.6 \mathrm{~m}$.To ensure the Safe of Danjiangkou Dam[1,2] heightening works. All existing cracks of old dam have been carefully checked. In particular, vertical cracks of the upstream face in 18th section may propagate further under water pressure.

Propagation trend of cracks in 18th section is the focus of attention in the design, which includes the probability of cracks in old dam continuing to propagate after heightening and cracks in new heightening dam extending to the old dam through the whole dam. In order to design reasonable treatment of cracks, all of this must be analyzed in detail by three-dimensional finite element method, combing with stress intensity factor method of fracture mechanics.

\section{Principle and method of calculation}

Consider a cracked plate. We can distinguish several manners in which a force may be applied to the plate which might enable the crack to propagate. Irwin [3] proposed a classification corresponding to the three situations represented in Figure 1. From fracture models above we can assume that the type of cracks is opening mode crack under splitting water pressure in cracks.

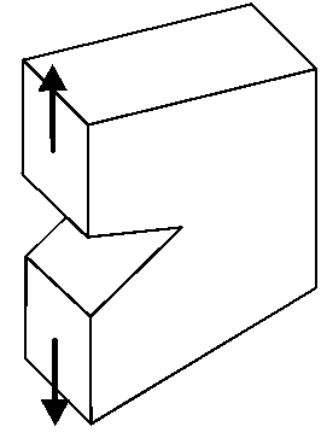

a)opening mode

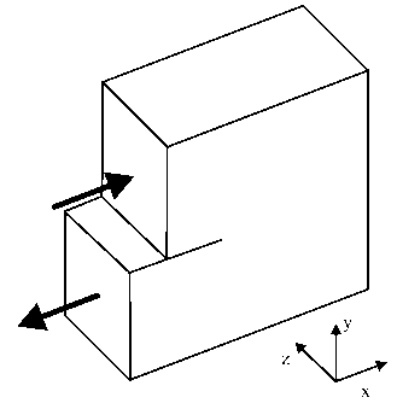

b)sliding mode

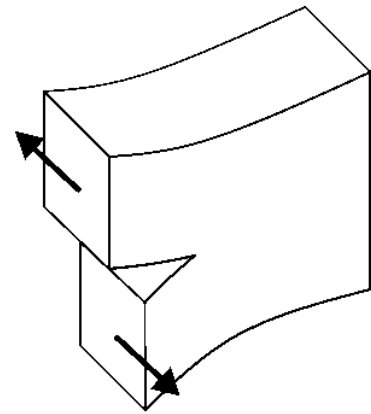

c)tearing mode

Fig.1 fracture models

From the viewpoint of fracture mechanics analysis [4], when stress intensity factor $\mathrm{K}_{\mathrm{I}}$ of the crack tip is greater than concrete fracture toughness $\mathrm{K}_{\mathrm{IC}}$, the crack tip will continue to propagate further. By three-dimensional finite element method [5], J-integral value around the crack tip is computed. 
Furthermore, stress intensity factor $\mathrm{K}_{\mathrm{I}}$ of is calculated through $\mathrm{J}$-integral value, by comparing with concrete fracture toughness, which determined whether to continue propagating.

Critical condition of cracks propogation is defined as:

$$
\mathrm{K}_{\mathrm{I}=} \mathrm{K}_{\mathrm{IC}}
$$

If stress intensity factor $K_{I}$ is greater than concrete fracture toughness $K_{I C}$, the crack tip will propagate further. According to the literature, the formula concrete fracture toughness $\mathrm{K}_{\mathrm{IC}}$ for the open-type crack is defined as [6]:

$$
\mathrm{K}_{\mathrm{IC}}=0.286 \mathrm{Rt}\left(\mathrm{MPa} / \mathrm{m}^{3 / 2}\right)
$$

Where Rt is splitting tensile strength of concrete, $\mathrm{k}$ is size effect coefficient and defined as 1.9 for mass concrete. According to the formula (2), if $\mathrm{Rt}$ is equal to $2.5 \mathrm{MPa}, \mathrm{K}_{\mathrm{IC}}$ is 1.35 by computing. When $\mathrm{Rt}$ is equal to $2.0 \mathrm{MPa}, \mathrm{K}_{\mathrm{IC}}$ is 1.08 by calculating.

\section{Computing model}

Vertical cracks of the upstream face in old dam should be generalized. Generalized models are shown in Fig.2.Two different conditions are considered:

(a) Vertical cracks of old dam are located at the elevation of 127-162m, where crack depth above the elevation of $151 \mathrm{~m}$ is $13 \mathrm{~m}$. The model is shown in Fig.2(a).

(b) Vertical cracks of old dam are located at the elevation of 76-162m, where crack depth below the elevation of $76 \mathrm{~m}$ is $13 \mathrm{~m}$. The model is shown in Fig.2(b).

Computing model is shown in Fig.3. Vertical cracks of the upstream face in new heightening dam are located between $162 \mathrm{~m}$ to $174 \mathrm{~m}$, where crack depth is $3.5 \mathrm{~m}$. The water level of normal operation is $170 \mathrm{~m}$.

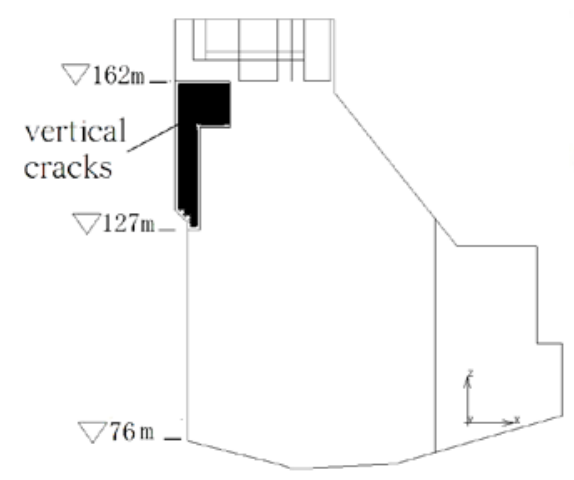

(a)

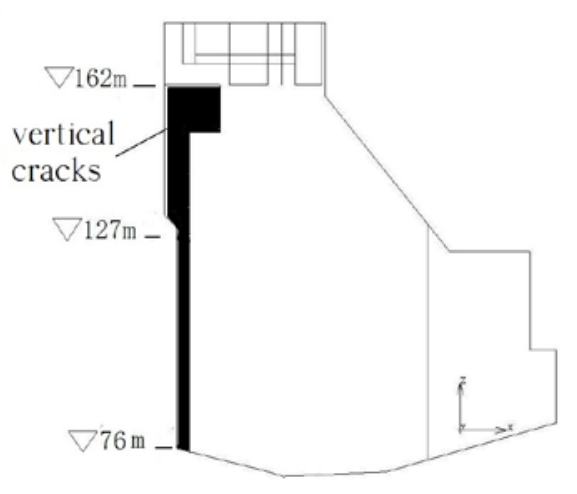

(b)

Fig.2 Generalized model of vertical cracks in old dam

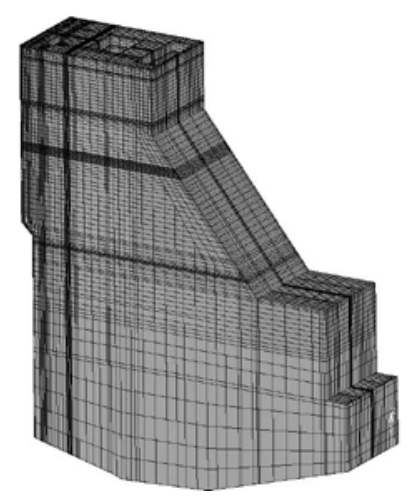

Fig.3 Computing model

\section{Computing scheme}

The stress intensity factor $K_{I}$ below the water level of $170 \mathrm{~m}$ is mainly calculated after the dam heightening, including drainage treatment of cracks. When drainage treatment of cracks is considered, the water pressure in cracks reduces with the decreasing cracks depth. Depending on the effect of drainage treatment, distribution of the water pressure in cracks is considered as:

(a)Distribution of the water pressure is regarded as Triangular distribution. At the upstream, the water pressure is considered as full head. At the crack tip, the water pressure is 0 .

(b)Distribution of the water pressure is regarded as Trapezoidal distribution. At the upstream, the water pressure is considered as full head. At the crack tip, the water pressure is 50 percent of full head.

(c)Distribution of the water pressure is regarded as Trapezoidal distribution. At the upstream, the water pressure is considered as full head. At the crack tip, the water pressure is 60 percent of full head. 
The stress intensity factor $K_{I}$ below the water level of $157 \mathrm{~m}$ in old dam before the dam heightening is calculated also for comparing with $\mathrm{K}_{\mathrm{I}}$ of new heightening dam.

\section{Computing results}

Analysis using the generalized model which is shown in Fig.2(a).The stress intensity factor $\mathrm{K}_{\mathrm{I}}$ of crack tip at different elevation along the flow is shown in Tab.1From the table, we can see that the maximum of $K_{I}$ for crack tip at different elevation is 0.52 under water level of $170 \mathrm{~m}$ and the water pressure of vertical cracks for new heightening dam is not enough and $K_{I}$ is less than 0.19 . The calculated $\mathrm{KI}$ is less than concrete fracture toughness, so possibility of cracks propagating further is low under water pressure in cracks.

The calculated $\mathrm{K}_{\mathrm{I}}$ after drainage treatment is also shown in Tab.1.From the table we can see that the stress intensity factor $K_{I}$ reduces with different magnitude after drainage treatment under different water pressure in cracks. For example, $K_{I}$ of crack tip reduces at the bottom elevation $(127 \mathrm{~m})$ is reduced respectively to $0.22,0.27,0.30$, so the possibility of crack propagation further is lower than that of no drainage treatment.

Tab1.stress intensity factor

\begin{tabular}{|c|c|c|c|c|c|}
\hline \multirow{4}{*}{ elevation (m) } & \multicolumn{5}{|c|}{ stress intensity factor $K_{I}$} \\
\hline & \multicolumn{4}{|c|}{$\begin{array}{l}\text { under water level of } 170 \mathrm{~m} \\
\text { after dam heightening }\end{array}$} & $\begin{array}{c}\text { under water level of } 157 \mathrm{~m} \\
\text { before dam heightening }\end{array}$ \\
\hline & \multirow[b]{2}{*}{ Full head } & \multicolumn{3}{|c|}{ drainage treatment } & \multirow[b]{2}{*}{ Full head } \\
\hline & & \begin{tabular}{c|} 
Triangular \\
distribution
\end{tabular} & $\begin{array}{l}\text { Trapezoidal } \\
\text { distribution }\end{array}$ & $\begin{array}{l}\text { Trapezoidal } \\
\text { distribution }\end{array}$ & \\
\hline 161 & 0.19 & 0.03 & 0.06 & 0.07 & 0.00 \\
\hline 156 & 0.24 & 0.08 & 0.14 & 0.18 & 0.03 \\
\hline 151 & 0.27 & 0.08 & 0.15 & 0.17 & 0.05 \\
\hline 139 & 0.36 & 0.14 & 0.18 & 0.21 & 0.20 \\
\hline 127 & 0.52 & 0.22 & 0.27 & 0.30 & 0.35 \\
\hline
\end{tabular}

Analysis using the generalized model which is shown in Fig.2(b).Under water level of $170 \mathrm{~m}$ the stress intensity factor $K_{I}$ of crack tip above the elevation of $127 \mathrm{~m}$ along the flow is the same as the calculated $\mathrm{K}_{\mathrm{I}}$ of the previous paragraph. So the main concern of this paragraph is the calculated $\mathrm{K}_{\mathrm{I}}$ of bottom elevation $(76 \mathrm{~m})$, where the calculated $\mathrm{K}_{\mathrm{I}}$ is maximum.

As shown in Table 2, after dam heightening, the calculated $K_{I}$ at the elevation of $76 \mathrm{~m}$ is 1.0 , which increases comparing with that before dam heightening, but it is less than concrete fracture toughness. After drainage treatment, KI of crack tip reduces at the bottom elevation $(76 \mathrm{~m})$ is reduced respectively to $0.45,0.73,0.78$.

Analysis shows that: under water level of $170 \mathrm{~m}$ after dam heightening, the maximum of $\mathrm{K}_{\mathrm{I}}$ at the elevation of $76 \mathrm{~m}$ (Dam heel) is less than that of dam heel before dam heightening, so cracks in old dams may not propagate further.

Tab2.stress intensity factor

\begin{tabular}{|c|c|c|c|c|c|}
\hline \multirow{3}{*}{ elevation (m) } & \multicolumn{4}{|c|}{ stress intensity factor $\mathrm{K}_{\mathrm{I}}$} \\
\cline { 2 - 5 } & \multicolumn{4}{|c|}{$\begin{array}{c}\text { under water level of } 170 \mathrm{~m} \\
\text { after dam heightening }\end{array}$} & $\begin{array}{c}\text { under water level of } 157 \mathrm{~m} \\
\text { before dam heightening }\end{array}$ \\
\cline { 2 - 5 } & \multirow{3}{*}{ Full head } & \multicolumn{3}{|c|}{ drainage treatment } & Full head \\
\cline { 2 - 5 } & 1.0 & $\begin{array}{c}\text { Triangular } \\
\text { distribution }\end{array}$ & $\begin{array}{c}\text { Trapezoidal } \\
\text { distribution }\end{array}$ & $\begin{array}{c}\text { Trapezoidal } \\
\text { distribution }\end{array}$ & 0.80 \\
\hline 76 & 0.45 & 0.73 & 0.78 & 0.80 \\
\hline
\end{tabular}




\section{Conclusion}

1)Propagation trend analysis of vertical cracks for 18th section shows that all calculated stress intensity factor is less than concrete fracture toughness by stress intensity factor method of fracture mechanics,

Which can illustrate that the possibility of crack propagating further is little under pressure of normal water level.

2)Under water level of $170 \mathrm{~m}$ after dam heightening, the maximum of $\mathrm{K}_{\mathrm{I}}$ with drainage treatment is less than that under water level of $157 \mathrm{~m}$ before dam heightening, which shows that if cracks propagation do not happen before dam heightening, then cracks cannot propagate further after dam heightening.

3)Cracks in old dam must be repaired through drainage treatment, which can reduce the possibility of crack propagating further in the hydraulic fracturing effect. Investigation of new cracks for heightening dam must be carried on, and new cracks should be deal with reinforcing treatments in order to avoid cracks propagate through the top of the dam.

\section{Acknowledgements}

This work was financially supported by the Fundamental Research Funds for Central Public Welfare Research Institutes (CKSF2014054/CL; CKSF2014053/CL).

\section{References}

[1] Lv GuoLiang,Chen ZhiKang.Design for Danjiangkou Dam heightening project of Middle Route Project of South-North Water Transfer Project.Yangtaze River.2009(40):81-84(in Chinese)

[2] Fu Qingtan ,Zhou Qiujing ,Zhang Lei. Study on impact from heightening of Danjiangkou Dam on its crack stability.Water Resources and Hydropower Engineering,2013(44):29-34(in Chinese)

[3] G. R. Irwin. Fracture. Encyclopedia of Physics (Handbuch der Physic,Vol VI, Flugge (Ed.), Springer Verlag, Berlin 551-590, 1958.

[4] Brian Lawn. Fracture of Brittle Solids,2nd edition.Beijing:Higher Education Press.

[5] O.C.Zienkiewicz,R.L.Taklor Tthe finite element method,5nd edition. World Book Inc(2008)

[6] Zhu BoFang. Thermal stress and Temperature Control of Mass Concrete (in Chinese), ChinaElectric Power Press, 1999.3(in Chinese) 